\title{
Yeni Nesil Belediyecilik: Dijital Belediye Uygulamaları
}

\author{
Next Generation Municipalities: Digital Municipality Applications
}

\section{Yakup KARACA}

Ögrr. Grv., Aydın Adnan Menderes Üniversitesi, Çine MYO, yakup.karaca@adu.edu.tr https://orcid.org/0000-0002-6902-4057

\section{Namık Kemal ÖZTÜRK}

Prof. Dr., Muğla Sitkı Koçman Üniversitesi,

İ̈F, Kamu Yönetimi Bölümü,

nkozturk@mu.edu.tr

https://orcid.org/0000-0002-7264-4791
Makale Başvuru Tarihi: 21.11.2019

Makale Kabul Tarihi: 27.12.2019

Makale Türü: Araştırma Makalesi

\section{Anahtar \\ Kelimeler: \\ Yerel Yönetimler, \\ Dijital Dönüşüm, \\ Dijital \\ Belediyecilik, \\ E-Belediye, \\ Molenlanden \\ Belediyesi,}

\section{Keywords:}

Local Governments,

Digital

Transformation,

Digital

Municipalityc,

E-Municipality,

Municipality of Molenlanden,

\section{ÖZET}

Yüzyılımızın dijital dünyasında $Z$ kuşağının yükselişi ve bireylerin kamu yönetiminden beklentilerinin başkalaşması, kaynak sıkıntıları vb. faktörler kamu yönetiminin hizmet sunma anlayışında değişikliğe neden olmuştur. Ancak bu faktörler arasında sosyo-ekonomik hayatı ve kamu hizmetlerini çok boyutlu bir şekilde küresel ölçekte etkileyecek olan dijital dönüşüm en önemli unsurdur. Yapay zekâ, büyük veri gibi teknolojiler sayesinde gerçekleşen dijital dönüşüm ile birlikte kamu hizmetleri vatandaşlara daha kaliteli ve en hizlı şekilde sunulacaktır. Küresel ölçekteki dijital dönüşümle birlikte vatandaşa kamu hizmeti sağlayıcı en yakın birim olan yerel yönetimlerin değişimi ve dönüşümü de tartışma konusu olmuştur. Buradan hareketle çalışmada bir belediye binasina ihtiyaç olmadan belediyecilik mümkün mü? Belediyelerin dijital uygulamalarla hizmet sunumunun ötesinde de yeni nesil bir dijital belediyecilik gerçekleştirilebilir mi? gibi sorulara Molenlanden Belediyesi örnek alınarak cevap aranacaktır.

\section{ABSTRACT}

In the digital world of our century, the rise of Generation $Z$ and the metamorphosis of individuals' expectations from public administration, resource shortages and so on. factors have led to a change in public administration's understanding of service delivery. However, among these factors, digital transformation is the most important factor that will affect the socio-economic life and public services in a multi-dimensional way on a global scale. With the digital transformation realized through technologies such as artificial intelligence and big data, public services will be provided to citizens in a faster and better quality. Together with the digital transformation at the global scale, the change and transformation of local administrations, which is the closest unit to the public service provider to the citizen, has been the subject of discussion. From this point of view, is it possible to work as a municipality without a city hall? Can a next generation of digital municipalities be realized beyond the provision of services by municipalities to digital applications? Molenlanden Municipality will be used as an example. 


\section{GIRISS}

Günümüzde teknolojinin hızlı gelişimiyle birlikte küresel ölçekte bir dijitalleşme süreci başlamıştır. $\mathrm{Bu}$ kapsamda kamu yönetiminin sunduğu hizmetlerin birçoğu e-devlet, e-belediye gibi dijital platformlarla sunulmaya başlamıştır. Kamu yönetiminin yerel hizmet sunumunda en önemli unsuru olan yerel yönetimler de kaynaklarını etkin kullanarak vatandaşa kaliteli, ucuz, hızlı hizmet sunmak ve mevcut sorunlara çözüm üretmek için hızlı bir dönüşümle karşı karşıya kalmıştır. Bu doğrultuda birçok yerel yönetim birimi bilişim ve internet teknolojilerine başvurarak hizmetlerin bir kısmını bu kanallardan vermeye başlamışlardır.

Bu doğrultuda Türkiye'de E-Dönüşüm Türkiye Projesi, Vatandaş Odaklı E-Devlet, E-Belediye, Dijital Türkiye Projesi gibi dijital dönüşüme yönelik çeşitli projeler geliştirilmiş̧ir. Benzer şekilde yerel yönetimler de zaman ve kaynak tasarrufu sağlayarak daha katılımcı, şeffaf ve demokratik bir yönetimi mümkün kılacak şekilde kamu hizmetlerini vatandaşa dijital ortamlarda sunmaya başlamıştır. Ancak internet ve bilişim teknolojilerinin hız kesmeden ilerleyişi ile dijital araçların sayısındaki artış yerel yönetimlerin birçok hizmeti bu araçlardan istifade ederek sunmasına ve arayışlara yönelmelerine neden olmaktadır. Hatta bu gidişin üzerinde ayrıntılı bir şekilde duracă̆ımız Molenlanden Belediyesinde olduğu gibi binasız/mekansız belediyelere doğru bir yönelimi de gündeme getirmektedir. Bu doğrultuda çalışmamızda, yerel yönetimlerde dijital dönüşüm incelenerek, dijital uygulamaların her geçen gün çeşitlenmesiyle birlikte dijitalleşmenin bir sonraki evresinde belediyelerin neler yapabileceği üzerinde durulacaktır. Ayrıca dijital uygulamalarla destekli hizmet sunumunun ötesinde yeni nesil tümüyle dijital bir belediyeciliğin mümkün olup olmadı̆̆g konusu Molenlanden Belediyesi örneği üzerinden tartış1lacaktır.

\section{YEREL YÖNETIMLERDE DİJiTAL DÖNÜŞÜM}

21. yüzyılın dijital çağında teknolojinin hızla ilerleyişle birlikte nesnelerin interneti, büyük veri, siber sistemler, gömülü sistemler, bulut bilişim teknolojileri, yapay zekâ, öğrenen robotlar ve sanal gerçeklik gibi gelişmeler dijital dönüşümü sürecini hızlandırmıştır. Bu süreçte toplumsal hayatta önemli değişimler meydana gelmiştir. $\mathrm{Bu}$ değişimle birlikte vatandaşların yaşadıkları yerlerde kamusal hizmetlere ilişkin talepleri de giderek değişmiştir. $\mathrm{Bu}$ gelişmeler yerel yönetimleri vatandaş arzu ve taleplerini karşılama, daha şeffaf, hesap verilebilir, katılımcı ve demokratik olma noktalarında değişime zorlamıştır. Benzeri gelişmeleri ülkemiz açısında geçerlidir. Türkiye'de de vatandaşa en yakın yönetsel birim olan yerel yönetimler kaliteli hizmet vermek ve verimliliği artırmak için bilgi ve iletişim teknolojilerine gittikçe daha fazla yatırım yapmakta ve kaynak ayırmaktadırlar (Kaypak, 2009:215). Sürekli gelişen bilgi ve iletişim teknolojileri yerel yönetimlerin dönüşümünü hızlandırmakta, yerel hizmet anlayışında yeni ufuklar açarak hizmet kalitesinin artmasına ve vatandaşın daha kolay erişmesine imkân sunmaktadır. Yerel yönetimlerin dijital dönüşümü yerel hizmet sunumunda kalitenin artmasına, vatandaş beklentilerine ve taleplerine duyarlı bir anlayışın ortaya çıkmasına ve hizmet maliyetlerinin düşmesine katkı sağlamaktadır.

Yerel yönetimler, kaynaklarını etkin ve verimli kullanarak vatandaşa kaliteli hizmet sunmak ve vatandaş katılımını gerçekleştirmek gibi temel amaçlarını gerçekleştirmek için dijital çağın gereksinimi olan bilgi ve iletişim teknolojilerine yatırıma yönelmişlerdir (Kaypak vd., 2017:1800). Dijital çağ öncesi hizmet sunumunu geleneksel yönetim anlayışıyla gerçekleştiren yerel yönetimler dijital çağla birlikte, dünyadaki gelişmeleri yakından takip edebilme olanağı yakalayarak daha demokratik, etkin, verimli, şeffaf, hesap verilebilir ve katılımcı yönetim anlayışını gerçekleştirme imkânını yakalamışlardır (Kaypak vd., 2017:1801).

Belediyeler, yerel yönetim sistemi içerisinde vatandaşlara kentsel alanlarda kamu hizmeti sağlayan birimlerdir. Gelişen teknolojiyle birlikte yerel yönetimlerin en önemli hizmet sağlayıcı birimlerinden olan belediyelerin bazı hizmetleri internet ortamına taşıdıkları görülmektedir. Ayrıca birçok belediye sosyal medyadan da önemli ölçüde yararlanmakta ve interneti yaygın bir şekilde kullanmaktadır. Bu bakımdan ülkemizde gittikçe yaygınlaşan e-devletin yerel ayağı olan e-belediye uygulamaları, belediyelerde yeni yönetim anlayışının bir parçası olarak görülmelidir.

E-belediye kavramı e-devletten ayrı düşünülemez. E-devlet, kamu hizmetlerinin sağlanmasında ve vatandaşlara sunulmasında dijital çağın imkânlarının kullanılmasının ötesinde insan kaynaklarının ve hizmet anlayışını da kapsayan bir zihniyet değişimini ifade eder (Karkaya Polat, 2006:10). E-Belediye, belediyelerin bütünsel dijital dönüşümünü ifade eden bir süreçtir. Bu dönüşüm içerisinde belediye bünyesinde yer alan tüm birimlerin bilgi ve iletişim teknolojilerine entegre edilmesi gerekir (Pektaş, 2011:70). Kaypak'a göre e-belediye, e-devletin yerel ayağı olarak ortaya çıkan bilgi ve iletişim teknolojilerinin imkânlarından faydalanılarak sunulan yeni hizmet 
anlayışının bir yansımasıdır (2009:225). Merter ise e-belediyeyi vatandaşların teknolojik altyapıları kullanarak belediyelerin karar alma süreçlerine katılımını sağlayan teknoloji tabanlı bir uygulama olarak değerlendirmektedir (2012:25). E-belediye, kent verilerinin bilişim teknolojilerin desteğiyle yönetilerek bu verilerden kent ve kentli yararına bilgiye dönüştürülerek vatandaş hizmetine sunulmasını ifade etmektedir (Henden ve Henden, 2005:52).

E-Belediye kavramı belediye hizmetlerinin elektronik ortama taşınması gibi gözükse de, kapsamı aslında daha geniştir. E-belediye bilgi ve iletişim teknolojilerinin kullanılması yoluyla daha şeffaf, etkin, verimli, vatandaşa daha yakın ve onun katılımını esas alan bir yapıyı ifade eder. Bu bakımdan e-belediye kavramı yerel hizmetlerin web sitesi aracılığı ile elektronik ortama taşınmasından öte arka planda gerçekleşmesi gereken değişimi de anlatır. Bu değişim vatandaş-müşteri odaklı hizmet anlayışının yerleşmesi, yeni bir idari yapının oluşturulması, dijital teknolojileri anlayan ve kullanabilen insan kaynağının yetiştirilmesi gibi kapsamlı bir dönüşümü gerektirir (Karakaya Polat, 2006:10).

E-devlet, e-belediyecilik gibi dijital uygulamalar sadece kamu hizmet sunumunda maliyetleri azaltan bir uygulamanın ötesinde profesyonel, akılcı, şeffaf, denetlenebilir, katılımcı ve etkin bir kamu yönetiminin de temel gereksinimlerindendir (Mecek, 2017:1816). Bu nedenle belediyelerin dijital dönüşümü vatandaşlara kamu hizmet sunumu sürecinde zaman ve maliyet tasarrufu sağlayarak hizmetlerinin daha hızlı, şeffaf, verimli ve kaliteli bir şekilde sunulması noktasında önemli katkı sağlamaktadır. Dolayısıyla yerel yönetimlerde dijitalleşmenin amacı; kamu hizmeti süreçlerinde verimliğin ve etkinliğin sağlanarak hizmet alan tarafların yaşam kalitesini arttırmaktır (Aksu, 2018:145-146). Ancak gün geçtikçe teknolojinin olanakların artmasıyla sağlanacak fayda da çeşitlenmektedir. Bu çeşitlilik dijitalleşmenin temel amacı olan verimlilik, etkinlik ve iyi yönetişim ilkelerinin tam manasıyla hayata geçirilmesi olarak aşağıda şsekil 1'de üç başlık altında gruplandırılabilir (Aksu, 2018:145).

Şekil 1. Dijitalleşmenin Amacı.

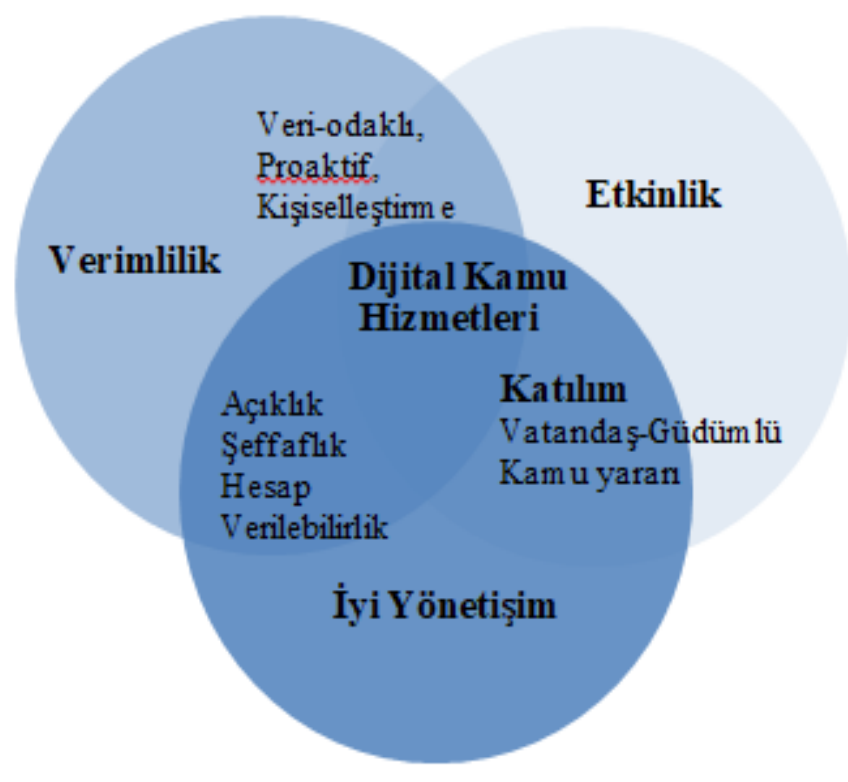

Kaynak: Aksu, 2018:145-146.

Dijital dönüşüm yerel yönetimlerde özellikle belediyelerde birçok yeniliği de beraberinde getirmesinin yanında hem belediyeler hem de vatandaşlar açısından önemli olanaklar sağlamıştır. Bu kapsamda belediyelerde kamu hizmet sunumunda dijitalleşmenin faydaları şöyle özetlenebilir;

- Vatandaş, belediyelerin gerek karar alma süreçlerine katılımları bakımından gerekse hizmet sunumunda yer ve zaman sınırının değişmesiyle daha hızlı hizmet alma imkânına sahip olmuştur (Pektaş, 2011:70). Dolayısıyla Hizmet üretme ve hizmete erişim süresi kısalmıştır.

- Belediyelerin hizmet sunum maliyeti ve vatandaşın hizmete katlanma maliyetlerinde azalma meydana gelmiştir (Henden ve Henden, 2005:59).

- Belediyeler kamu hizmeti sunumunda sadece yerel halkla sınırlı kalmaksızın daha büyük kitlelere ulaşabilme firsatı yakalamıştır (Pektaş, 2011:70). 
- E-devlet, e-belediye gibi vatandaşın hayatını kolaylaştırıcı uygulamaların ortaya çıkmasının önü açılmıştır (Kaypak vd., 2017:1801).

- Vatandaşların istek ve taleplerinin yerelde hızlı ve güvenilir bir şekilde karşılanması sağlanmıştır (Y1lmaz, 2019: 513).

- Daha kaliteli hizmet, vatandaş odaklı hizmet, 7 gün 24 saat gibi hizmet uygulamaları ortaya çıkmıştır (Karakaya Polat, 2006:119).

- Daha saydam ve hesap verilebilir bir yönetim anlayışı oluşmuş bu çerçevede belediye hizmetleri ve belediye yönetimlerinin aldıkları kararlar daha denetlenebilir hale gelmiştir (Şahin, 2007:168). Sunulan hizmetin hesap verilebilirliği ve denetimi kolaylaşmıştır.

- Vatandaşların hizmetten yaralanmak için katlandığı giderler azalmıştır.

- Dijital dönüşüm belediyelerde ortak akılda birleşme ve paydaş ruhunu ortaya çıkararak katılımcı bir anlayışın yerleşmesine ve demokratikleşme sürecine önemli katkılar sağlamıştır (Henden ve Henden, 2005:59).

- Gerek belediyelerin hizmet tasarım süreçlerinde vatandaş arzu ve beklentilerine daha kolay başvurabilme imkânı gerekse vatandaşın hizmet tasarım süreçlerine katılım imkânı gibi önemli firsatlar doğmuştur.

- Değişen hizmet anlayışıyla birlikte vatandaşın yerel yönetimlere olan güveninde önemli artış olmuştur (Henden ve Henden, 2005:59).

- Vatandaş ve yerel yönetimler arasında engeller ortadan kalkarak etkileşimin artması sağlanmıştır (Şahin, 2007:168).

- Belediyelerin vatandaş talep ve şikâyetlerine daha kısa sürede cevap verebilmesi sağlanmıştır (Şahin, 2007:168). Vatandaş görüşünün alınmasında kolaylık sağlanmıştır. Kamu hizmeti iş süreçlerinin takip edilebilirliği kolaylaşmıştır.

- Yerel yönetim birimlerinin kurumsal bilgi ve belgelerinin daha kolay saklanması sağlanmıştır (Kaypak vd., 2017:1801).

- Merkezi yönetim ile yerel yönetimler arasında bilgi akışının sağlanmasında kolaylıklar oluşmuştur (Şahin, 2007:168).

- Yerel yönetimlerin karar alma süreçlerinde bürokratik engeller ve kırtasiyecilik azalarak daha hızlı karar almaları ve bunları uygulayabilmeleri sağlanmıştır.

Dijital dönüşümle birlikte bilgi iletişim teknolojilerin kullanılması vatandaş odaklı sürdürülebilir bir yönetim anlayışının gerçekleştirilmesinde, yerel yönetimlere hizmetlerinin daha verimli, adil, etkin, şeffaf, katılımcı, hesap verebilir bir şekilde sunulmasının yollarını daha da açmıştır.

\section{DİJITTAL BELEDIYYECILIKK KAVRAMI}

Belediyeler dijital dönüşümle birlikte vatandaşın beklenti ve taleplerine cevap verme noktasında kendilerini yenileyerek daha aktif bir yapıya bürünmüşlerdir. Bu noktada Türkiye'de nüfus yoğunluğu fark etmeksizin hemen hemen bütün belediyeler kendilerine ait bir web sitesine ve sosyal medya hesaplarına sahiptirler. Ancak dijital belediyecilik, belediyelerin bir web sitesi üzerinden kendini tanıtması ve emlak vergisi, su faturası, yapı ruhsatı gibi sorgulamaların belediye binasına gitmeden internet üzerinden gerçekleştirilmesinin ötesinde bir anlam taşımaktadır.

Kayıtların bilgisayar ortamında dosyalanmasıyla ve birçok hizmetin internet ortamında verilmesiyle gündeme gelen dijital belediyecilik, teknolojik gelişmelerin artmasıyla birlikte anlam ve kapsam değişimine uğramıştır (Çapar, 2015:1). Dolayısıyla dijital belediyecilik bugünkü anlamıyla vatandaş ve yerel yönetimlerdeki tüm paydaşların etkileşimlilerinde uygulanan süreçlerin, bilgi ve iletişim teknolojileri araçlarıyla yönetilmesi ve tekrar erişilebilecek şekilde saklanması gibi faaliyetlerinin bütünü olarak tanımlanabilir (Çapar, 2015:1). 
Şekil 2. Dijital Belediyenin Odak Alanları

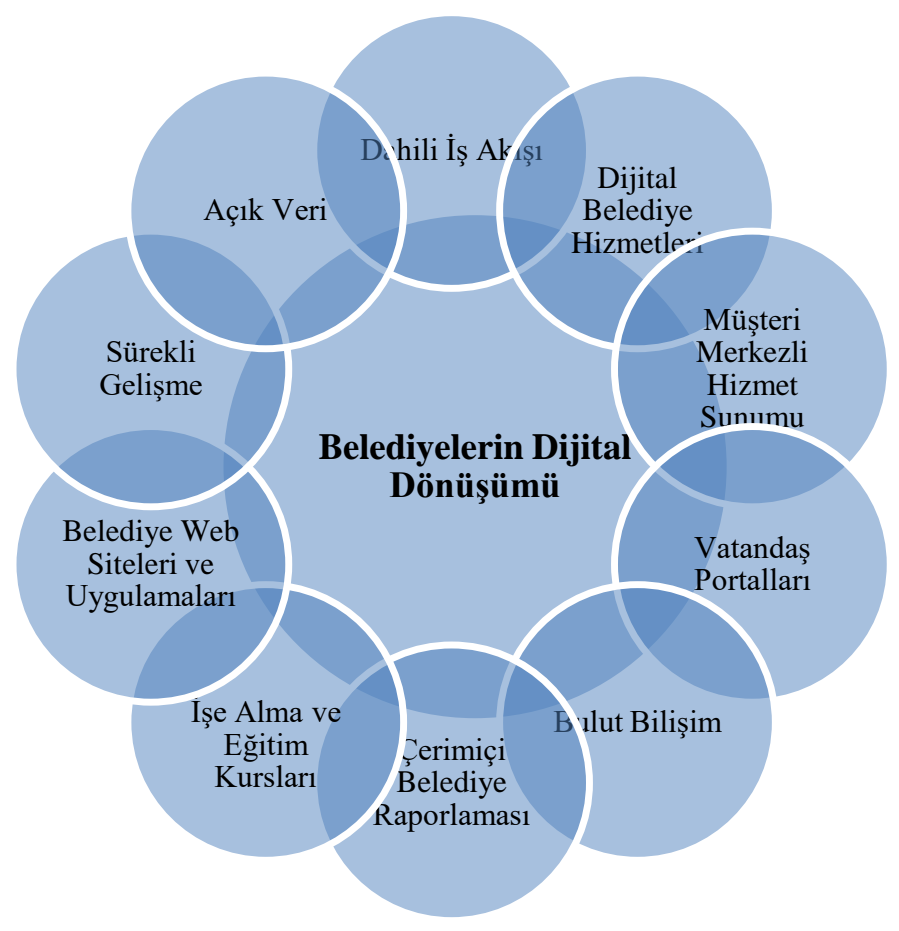

Kaynak: Murphy vd., 2018.

Dijital belediyecilik uygulamaları dünya genelinde ilk dönemlerde teknolojik sınırlamalar dolayısıyla insan kaynakları, muhasebe gibi gereksinimlerin kayıtlarının tutulduğu yazılımlarla başladı. Bu süreçte yazılım teknolojilerinin iletişim, haberleşme gibi birçok alanda başarılı bir şekilde kullanılması yazılım teknolojilerine güveni artırmıştır. $\mathrm{Bu}$ doğrultuda belediyelerde iyi yönetişim ilkelerini uygulamak üzere bütünleşik yazılım teknolojileri ve çeşitli dijital uygulamalar kullanılmaya başlandı (Çapar, 2015). Bu dijital uygulamalar, "e-devlet entegrasyonu, e-belediye yazılımı, Elektronik Belge Yönetimi Sistemi (EBYS), e-ruhsat başvuru sitemleri, edilekçe ve e-imza" şeklinde belirtilebilir. Bunların yanında "akıllı otobüs, akıllı durak, akıllı araç takip sistemleri, saha satış otomasyonlar, kioks uygulamalar, video-konferans, webcasting ve intranet uygulamalarl, çağrı merkezi telefon teknolojileri, mobil teknolojiler, atı yönetim sistemleri”, gibi araçlar vatandaşların yaşam koşullarını kolaylaştırmaya yardımcı olmaktadır (Karakaya Polat, 2006:40-41).

Tüm bu teknolojik gelişmeler sayesinde yönetimlerin işi hem kolaylaşmakta hem de zorlaşmaktadır. Zorlaşmasının sebebi; teknolojik imkânlardan faydalanmak için daha çok çaba ve uzmanlığa ihtiyaç duyulmasıdır. Çünkü nesnelerin interneti, artırılmış gerçeklik ve yeni dijital ve akıllı üretim teknolojileri alış1k olduğumuz fiziki mekânın ötesinde bir mekân sunmaktadır. Kolaylaşmasının sebebi ise siber mekânda gerçekleştirilen faaliyetlerin hemen hemen hepsi dijital hale gelmesinden ötürü bir yerlerde kaydedilmektedir (Aksu, 2018:150). Dolayısıyla dijital teknolojilerle birlikte mekân algısı değişime uğrayarak yeni bir "siberfiziksel mekân" gerçekliği ortaya çıkmaktadır (Aksu, 2018:151).

Dijital belediyecilik kavramı akıllı şehirler, bilgi şehirleri, dijital şehirler, ağ şehirler gibi kavramlarla benzeşen ve örtüşen bir kavramdır. Şehir politikaları kapsamında gerek küresel gerekse Avrupa ölçeğinde akıllı şehirler kavramı dijital belediyecilik kavramına baskın çıkmıştır. Bu nedenle dünyada akıllı şehirler kavramı daha yaygın kullanılmaktadır. Akıllı şehir kavramının zamanla evrilmesiyle akıllı şehircilik kavramı, teknoloji destekli şirketlerin öncülüğünde değil bizzat yerel yönetimlerin öncülügünde yürütülmektedir (Benli, 2018:2122). Özellikle vatandaşa en yakın yerel yönetim hizmet birimleri olan belediyelerde hizmet sunumunun gittikçe akıllı dijital uygulamalar sayesinde sunulmaya başlamasıyla gelecekte belediyecilik anlayışının tam manasıyla dijitalleşmesinin mümkün olup olmayacağı konusunda yeni tartışma ortamı doğmaktadır. Bu tartışmalar, belediye başkanları ve şehir yöneticileri ve şehirlerin tüm paydaşlarıyla birlikte şehirlerin geleceğinin ne olması gerektiğine, dijital teknolojilerin ve inovasyonun nasıl rol oynayacağına, (Benli, 2018:21-22) ve bu süreçte dijital belediyecilikte güvenliğin nasıl sağlanacağına dair tartısmalardır. Bu noktada dijital belediyecilikte en temel tartı̧̧ma güvenlik ve yazılım konusundadır. Çünkü dijital belediyecilikte en temel sorun; 


\begin{abstract}
"yazllım üreticilerine olan bağımlılık sorunu ve bulut teknolojilerinde kullanılan ürünlerin, bulut için yazılmış olmamalarıdır. Hali hazırda kullanılan ürünlerin bir kısmı, web tabanlı geliştirilmiş bir ürünün, bulut servisi olarak kullanılması şeklindedir. Bu durum teknolojik bazı handikaplar doğurmakta, bant genişliği ihtiyacını yükseltmekte ve kullanımda bazı sorunlar çıkarmaktadır. Özellikle küçük belediyelerin ihtiyacını karşılamak amacıyla merkezi bir kurum tarafindan tamamen bulut teknolojisi ile hazırlanmış bir ürünün geliştirilmesi yönünde yapılacak çalışmalar bu sorunları da ortadan kaldıracaktır" (Çapar, 2015).
\end{abstract}

Dijital belediyecilik uygulamalarında, "nesnelerin interneti, büyük veri, açık veri, bulut bilişim artırlmış gerçeklik, robot teknolojileri, blokzincir, mobil teknolojiler, merkezi denetleme, kontrol ve veri toplama sistemleri" gibi gelişen teknolojiler sıkça kullanılmaktadır (Benli, 2018:23). Belediyelerin hizmet sunumunda kullanılan bu tür dijital uygulamaların hızla gelişmesi yeni nesil belediyeciliğin, fiziki bir belediye mekânı olmaksızın siber-fiziksel mekânda daha modern bir belediyeciliğin gerçekleştirilebileceği gerçeğini göstermektedir.

Dünyada Barselona, Singapur, Rio, San Fransisco, Kopenhag, Londra, Viyana, Amsterdam, Tokyo, New York ve Seul gibi şehirler dijital şehir, akıllı şehir uygulamalarında dikkat çeken örnek şehirler arasındadır (Benli, 2018:229. Örneğin New York'ta "akustik silah sesi izleme sistemi” kurulmuş ve bu sistem sayesinde bir silah ateşlendiğinde sistem en yakın polis merkezine uyarı göndermektir. Tokyo'da ise şehirde aydınlatma için yüksek verim sağlayan cihazlarla konutların ne kadar 1sıtılması gerektiğini hava durumuna göre belirleyen bir sistem kurulmuş ve bu sayede şehirde hem enerji tasarrufu sağlanmakta hem de çevre kirliliğinin önüne geçilmektedir. Yine San Fransisco Belediyesi "SFpark" isimli mobil uygulama ile otoparklara yerleştirilen sensörler sayesinde vatandaşların boş park yerlerini kolayca bulmalarını sağlamaktadır (Dijitalyazarlar, 2019). $\mathrm{Bu}$ şehirler, vatandaş hayatını kolaylaştırmak ve yeni nesil dijital şehirleri yönetebilmek için vatandaş katılımlı ve teknoloji destekli dijital şehir modelini uygulamaya başlayan örneklerdir (Benli, 2018:22). Ancak tam manasıyla dijital şehir modeli açısından belediyeciliğin siber-fiziksel mekânda gerçekleştirilmesi konusunda belediye binası olmadan tamamen dijital bir belediyecilik örneği sergileyen Hollanda'nın Molenlanden Belediyesi bu modeli dünyada ilk ve tek hayata geçiren belediye olarak öne çıkmaktadır.

\title{
4. DİJİTAL BELEDIYYE UYGULAMASI: HOLLANDA'NIN MOLENLANDEN BELEDIYYESİ
}

Hollanda'da belediyeler biçim ve görevleri itibariyle farklı yapıdadırlar. Tüm belediyelerin görevleri aynı olmalarına rağmen görevleri yerine getirme biçimleri bakımından farklılaşmaktadırlar. 400'den fazla belediyesi olan Holanda'nın en büyük belediyesi yaklaşı 750.000 nüfusa sahip Amsterdam Belediyesi iken en küçük nüfuslu belediye ise 1000 kişilik nüfusla Schiermonnikoog Belediyesidir (Karkın, 2013:296-297). Hollanda'da belediye sayısı 400 'den daha yüksekti, ancak bazı politika ve hizmetlerin gerçekleştirilmesi büyük idari örgütsel yapıları zorunlu kılması nedeniyle komşu belediyelerin birleştirilmesi yoluna gidildi. Bu birleşmeler nedeniyle Hollanda'da belediye sayıs1 390'a düşmüştür (Erdoğan, 2019:64). Hollanda'da küçük nüfuslu komşu belediyelerin bu şekilde birleştirilmesi uygulamaları halen devam etmektedir (VNG, 2018:27). Bu konuda, bir araştırma merkezinin yerel yönetimlerde verimliliği sağlamak ve bütçe sorunlarının önüne geçilmesi için belediye sayılarının yeniden düzenlenmesi hususunda merkezi yönetime önerilerde bulunmuştur. Ancak dönemin hükümeti bu öneriyi dikkate almayarak belediyelerin sayılarına ilişkin kararın belediyelerin kendi iradeleri ile alınması gerektiğine işaret etmiştir. Böylece belediyelerdeki birleşme merkezi yönetim eliyle değil, belediyelerin kendi iradeleriyle gerçekleşmiştir (Karkın, 2013:297).

Hollanda'da belediye seçimleri 4 yılda bir yapılmaktadır ve belediyeler, belediye meclisi, belediye encümeni, belediye başkanı ve başkan yardımcılarından oluşmaktadır (Erdoğan, 2019:64). Belediyelerin en tepesinde belediye meclisi bulunmaktadır. Belediye meclisi yerel düzeyde bir yasama organı işlevini göstermektedir. Şehirlerin büyüklügüne göre belediye meclisi üye sayıları 7 ile 45 arasında değişiklik göstermektedir. Belediye meclis üyeleri 4 yılda bir gerçekleştirilen seçimle başa gelmektedirler (Karkın, 2013:298-302). Meclise belediye başkanı başkanlık etmektedir (Erdoğan, 2019:64). Belediye başkanı ise seçimle değil yerel seçilmişler tarafından İçişleri ve Kraliyet İlişkileri Bakanı'na sunulan iki aday arasından Bakan tarafından atamayla göreve gelmektedir. Belediye başkanı, aynı zamanda belediye meclisinin ve belediye yürütme konseyinde başkanıdır. Belediye başkan yardımcıları ise belediye seçimleri sonucunda koalisyonda anlaşan siyasi partiler tarafından belirlenmektedirler. Bu yüzden belediye başkan yardımcılarının siyasal kimlikleri daha fazla ön plandadır. Belediye başkan yardımcılığı nüfusu 18.000 'in altında olan belediyelerde yarı zamanlı olarak gerçekleştirilmektedir. Küçük belediyeler için belediye başkan yardımcılarının sayısı iki iken büyük çaplı 
belediyeler için bu yası yediye kadar çıkmaktadır (Karkın, 2013: 298-302). Vatandaşları ilgilendiren konularda denetleme yapmak, meclisin çıkardığı yönetmeliklerin yürütülmesi ve meclise sunulacak tasarıların hazırlanmasından sorumlu olmak gibi görevleri bulunan belediye encümeni ise belediye meclisi üyeleri arasından seçilen sayıları belediye nüfusuna göre 2 ila 8 arasında değişen bir organdır (Erdoğan, 2019:64).

Molenlanden Belediyesi, 2013 yılında Hollanda'da üç küçük belediyenin (Graafstroom, Liesveld ve NieuwLekkerland) birleşmesinden meydana gelen Molenwaard belediyesine 1 Ocak 2019'da Giessenlanden Belediyesinin katılımıyla Molenlanden isminde birleşen, Güney Hollanda eyaletinde $192 \mathrm{~km}^{2}$ alana sahip olan 43.858 nüfuslu bir belediyedir (https://www.molenlanden.nl).

Halmos'a göre; bu birleşmenin amacı Hollada'daki belediyelerin kamu harcamalarını daha rasyonel hale getirmekti. Ancak bu birleşme bütün belediyelere merkezi bir konumda olacak bir belediye binası sorununu ortaya çıkardı. Bu nedenle, yerel belediye meclisi belediye binası olmadan tüm hizmetlerin dijital bir ortamda sunulmasına karar vermesiyle sanal bir dijital belediye yapısı inşaa edildi. Böylece fiziksel bir belediye binasına sahip olmadan, belediye binasının yapım ve kullanım maliyetlerinden de kaçınılmış olundu (Halmos, 2016). Molenlanden Belediyesi başlangıçta Molenwaard ismiyle düşük bütçeli bir fiziksel belediye binasıyla dijital belediyeciliğin denemesini gerçekleştirdiler. Bu kapsamda belediye memurlarına esnek çalışma imkânları tanındı. Daha sonra dijital belediye projesi hayata geçirilince mevcut belediye binasının kapıları kapatıldı ve sanal belediyeciliğe geçildi. 1 Ekim 2014'ten beri yerleşik fiziksel bir konumu olmayan belediye, tüm kamu hizmetlerini dijital mekânda gerçekleştiren dünyadaki ilk belediyesi olmuştur (Beltz, 2016).

Molenlanden Belediyesisinin fiziki bir konumu bulunmamaktadır. Ancak belediyenin mali idare gibi bölümlerinin sadece personel için tasarlanmış bir ofisi bulunmaktadır. Bu ofisslerde vatandaş ziyaretlerini karşılayacak bir ziyaretçi masası bulunmamaktadır (OGD, 2013). Vatandaşlar taleplerine göre bir belediye yetkilisiyle görüşme gerçekleştirmek istiyorsa belediyeden randevu almaktadırlar ve belediye görevlileri vatandaşların talepleri doğrultusunda konutlarında ya da bir kafede ziyaret ederek görüşme gerçekleştirmektedirler (Molenlanden Belediyesi, 2019).

Molenlanden Belediyesi örneğinde, Belediye memurları çalışma alanlarına göre belirli miktarda para alırlar ve evde (Bulutta) çalışmaktadırlar. Memurlar görsel kimlik doğrulaması gerektiren (pasaport, ehliyet ve kimlik kartı) durumlarda vatandaş ziyaretleri gerçekleştirmektedirler. Belediye toplantıları yerel topluluk mekânlarında, kafe, bar gibi yerlerde gerçekleştirilmektedir. Vatandaşların dijital belediyeden en iyi şekilde yararlanmaları için tüm vatandaşların kolayca erişim sağlayacağı şekilde tasarlanan bir belediye portalı oluşturulmuştur. Oluşturulan bu dijital belediye portalına erişim sağlayan her ziyaretçi, ziyaret sebebini seçtikten sonra belediyeden talep edeceği hizmet konusunda sistem tarafından yönlendirilmektedir. Vatandaşlar belediyeden bir randevu talebinde bulunacakları zaman kendilerine en uygun ve en yakın bir yeri belirleyebilmektedirler. Örneğin, pasaport başvuruları için belediye sınırlarındaki köylerde birden fazla başvuru merkezi belirlenmiştir ve vatandaşlar kendilerine en yakın başvuru merkezini talep ederek işlemlerini gerçekleştirebilmektedirler. Vatandaşlar diğer belediye hizmetleri için ise daha geniş dijital bir ön büro seçeneğine sahiptirler. Benzer şekilde belediye meclisinin toplanma yerinde herhangi bir kısitlama bulunmamaktadır. Belediye meclisi huzurevinde, bir spor salonunun veya bir şirketin kantininde vb. yerlerde toplanabilmektedirler. Belediye meclis toplantılarının yapılacağı yer çoğunlukla toplantı gündemine ve tartışılacak konuya göre seçilmektedir. Böylece, belediye meclisinde tartışılacak konunun ilgilileri tarafından karar alma süreçlerine katılımlarının sağlanması da kolaylaşmaktadır. Benzer durum memurlar içinde geçerlidir. Memurlara, kendilerine en uygun yerlerde çalışabilme gibi esnek çalışma imkânıyla her zaman ve her yerde vatandaş odaklı bir şekilde çalışmaları sağlanmıştır. Böylelikle memurlar, ister evde, ister bir kafede isterse kendine uygun bir ofis ortamı oluştuğu yerlerde çalışabilmektedirler. Tüm bunların yanında vatandaşların ziyaret edebileceği bir fiziki mekânın olmayışından ötürü pasaportların ve belediyeden alınacak diğer tüm belgelerin vatandaşlara evlerinde veya işyerlerinde hızlı, güvenli bir şekilde ulaşmalarını sağlayacak özel bir teslimat hizmeti de oluşturulmuştur (Bletz, 2016).

Molenlanden Belediyesi, OGD Bilgi İletişim Teknolojileriyle akıllı çevrim içi hizmet sunarak daha iyi hizmet vermek adına, "Office 360" ve "Azure" hizmetleriyle Microsoft bulut teknolojisini kullanmaktadır (OGD, 2013).

Vatandaşlarla iletişim kurmak içinse "Skype" uygulaması kullanılmaktadır. Belediyede Microsoft, bulut bilişim hizmetlerinin kullanılmasının sebebi; ucuz olması ve vatandaş verilerinin korunması konusunda daha güven duyulmasıdır. Molenlanden sanal belediyesi, 2015 yılında Microsoft tarafından "yenilikçi fikirler" kategorisinde Yılın Akıllı Şehri’ne aday gösterilmiştir (Bletz, 2016). 
Molenlanden dijital belediyesinin hayata geçirilmesinin amacı sadece para tasarrufu yapmak değildi, asıl amaç yönetişim ilkelerini hayata geçirmek ve hizmetlerin kalitesini artırarak vatandaş yaşamını da kolaylaştıracak faaliyetlerde bulunmaktı. Yerleşik bir belediye binasını hayata geçirmek için 15 milyon Euro'ya ihtiyaç vardı. Ancak dijital belediyeyi hayata geçirmek için 3 milyon Euro harcandı. Dijital belediyeciliğin faydaları göz önüne alındığında bu miktarın yerleşik bir belediye binasının maliyetinden de öte çok daha düşük kalmaktadır (Gemeente.nu, 2015).

Dijital belediye hayata geçirildiğinde vatandaşlar, belediye idari süreçlerinin işleyişini eskisine göre daha kolay takip etme imkânına kavuşmuştur. Dijital belediyecilik vatandaşları doğrudan etkileyen bir konuda karar alınacağı zaman onları bilgilendirmek ve fikir ve görüşlerini almak için mesajlaşma servine abonelik konusunda teşvikler yapmaktadır. Belediyenin pek çok veri türü çevrimiçi olarak halka açıktır. Ayrıca vatandaşlar belediye meclis kararlarına dijital olarak katılım sağlayarak tepki verebilme imkânına sahiptirler (Bletz, 2016).

Tüm bunların yanında Molenlanden belediyesinin bazı dijital hizmetleri şu şekildedir; Belediye atık yönetimi çerçevesinde atıkları bir özel şirkete toplatmaktadır. Atık toplama istasyonları oluşturup, atık toplama takvimine göre vatandaşlar posta kodu ve ev numarasını dijital ortamda girerek hizmetten yararlanabilmektedir. Ayrıca özel şahıslar ve kurum kuruluşlarla iş birliğini hâkim kılarak yerel kalkınma projelerinin oluşturması için bir girişimci sayacı uygulaması oluşturulmuştur. Birlikte yaşam programları vasıtasıyla da belediyede yaşayan sakinlere ve çalışanların değerlerine uygun biçimde öncelikli ele alınması gereken konuları tartışmak ve gelecek yıllarda karşılaşılabilecek zorluklar konusunda sakinler ve tüm paydaşlarla birlikte tartışma toplantıları düzenlenmektedir. Vatandaşların belediye yetkilileriyle dijital ortam dışında şahsen görüşmek için bir randevu portalı oluşturulmuş ve bu sayede önceden belirlenen hizmet noktalarında yetkililerle görüşme sağlanabilmektedir. Bunun yanında doğum ve ölüm bildirimleri dijital ortamda alınmaktadır. Cenaze ve mezarlık işlemleri için sistemin verdiği bir şifre ile giriş sağlanarak cenazenin hangi gün ve saatte alınacağı, mezarlık ve mezar seçimi işlemleri de gerçekleştirilebilmektedir. Toplantı ve etkinlik düzenleme, işyeri lisansı alma, işportacılık yapmak, şans oyunları lisansı gibi konularda bir izin portalı yardımıyla başvuruların alınması gibi birçok hizmet dijital olarak gerçekleştirilmektedir (Molenlanden Belediyesi, 2019).

Belediyenin hizmet kalitesinin artması dijital belediyecilik projesi sayesinde gerçekleşmiştir. Bu kalitenin yakalanmasında ki en önemli sebep ise belediye memurları ve vatandaşların eski uygulamalara nazaran hem birebir hem de dijital olarak eskisinden çok daha fazla etkileşimde bulunmalarıdır (Erdoğan, 2019:71). Bunun yanında vatandaşların, Molenlanden'de karar alma ve kararların uygulanması sürecine daha fazla dâhil olmaları, alınan kararlara anında dijital tepki verebilme imkânına sahip olmaları gibi etmenlerin vatandaşı yönetimin etkin bir parçası haline getirmesi gibi önemli faktörlerin de rolü büyüktür (Bletz, 2016).

Tilburg Üniversitesi tarafından yapılan bir araştırmaya göre, belediye işlemleri sayısallaştırılmadan önce vatandaşlar belediye hizmetlerine 10 üzerinden 8 puan vermiş̧ir. Dijital belediyeciliğe geçildikten sonra ise vatandaşların belediye hizmetlerine puanı 10 üzerinden 9 olmuştur (Bletz, 2016).

\section{SONUÇ}

21. yüzyılın dijital çağında bilgi iletişim teknolojilerinin gelişmesi, dijital araç ve uygulamaları kullanan, internete bağlanan insanlarının sayısında önemli artışlar meydana getirmiştir. Artık günümüzün $Z$ kuşağı diye bilinen internet ve teknoloji ile büyüyen kuşak, çok küçük teknolojik araçlarla bile dünyanın her tarafındaki enformasyona kolayca erişim sağlayabilir bir imkâna sahip olmuştur. Dolayısıyla dijital araçların sayıları, hızları ve işlevleri gibi imkânlar artıkça toplumların birbirine bağlantılılık düzeyini de günden güne artmaktadır. Bu kapsamda milyonlarca insan teknolojik araçlar vasıtasıyla dijital ortamda içerik üretmektedir. Dijital çağın bu yeni kendini özgürce ifade etme ve özgürce iletişim, haberleşme hareketi vatandaşların kamu yönetimlerinden beklentileri, talepleri ve hesap sorma arzularını da artmıştır.

Dünyamızda teknolojik gelişmelere bağlı olarak yaşanan dijital dönüşüm akıllı robotlar, yapay zekâ gibi unsurlar fiziksel ortam ile sanal gerçekliliği birleştirmeyi vaat etmektedir. Küresel ölçekte dijital dönüşüm ve toplumluların birbirlerine bağlantılıkları arttıkça; yönetimler de ya kendini bu dönüşüme uyarlayacak ya da günümüz teknoloji kuşağına uyum sağlayamaz duruma düşme riskiyle karşı karşıya kalacaktır. Bu kapsamda dünyada yaşanan dijital dönüşümle birlikte karşıllklı etkileşimler paralelinde yerel yönetim hizmetlerinde dijital uygulamaların sayısında artış yaşanmıştır. Yerel yönetimlerin hizmet sunumlarında dijital araçları kullanmaları; bürokrasi ve kırtasiyeciliğin azaltılması, iyi yönetişim ilkelerinin hayata geçirilip hizmetlerin şeffaf, denetlenebilir, etkin, verimli ve katılımcı bir biçimde sunulması, hizmetin zaman ve maliyetini düşürme, hizmet 
kalitesinin arttırılarak vatandaşın yaşamının kolaylaştırılması ve daha demokratik bir yönetimin gerçekleştirilmesi gibi hususlarda önemli katkıları olacaktır.

Dijital belediyecilik anlamında çalışmada ele alınan Hollanda'nın Molenlanden Belediyesinde fiziki bir belediye mekânı olmaksızın siber-fiziksel mekânda bir belediyeciliğin gerçekleştirilebileceği gerçeğini göstermektedir. Dijital belediyeciliğin geldiği bu nokta 43.858 nüfuslu bir belediyede kamu hizmetlerinin neredeyse tamamının dijital ortamda gerçekleştirilmesi hizmet kalitesinin artması, insan hayatının kolaylaşması, yerleşim yerlerinin daha yaşanabilir kılınması gibi çeşitli pozitif faktörler açısından geleceğe dair umut verici gelişmedir. Dijital belediyecilik konusunda yaşanan bu gelişmeler Türkiye'deki belediyeler ve büyükşehir belediyeleri için adeta bir yol gösterici niteliktedir. Türkiye'de büyükşehir belediyelerinde "Araç Takip Bilgi Sistemi, Akıllı Sinyalizasyon, Trafik Kontrol Merkezi, atık yönetimi için Çevre Kontrol Merkezi, akıllı kart ve akıllı cihazlar" gibi dijital uygulamalar kullanılmaktadır. Bunun yanında E-devlet üzerinden vatandaşların kullanımına sunulan e-belediye bilgi sistemi ile ruhsat başvurusu, ruhsat başvuru sorgulama, dilekçe kayıt, belediye bilgi edinme başvuruları, evrak takibi gibi hizmetlerde verilmektedir (İçişleri Bakanlığı E-Belediye, 2019). Ancak Türkiye'deki belediyelerin bu tür sınırlı dijital uygulamaları kullanmasının ötesinde Molenlanden belediyesi örneğinden hareketle cevaplanması gereken soru, "bir belediye binası olmadan dijital bir belediyecilik gerçekleştirilebilir mi?" sorusudur. Bu tür bir belediyeciliğin gerçekleştirilebilmesi için en önemli unsur yerelde merkezi yönetim birimleriyle işbirliğini hâkim kılmaktır. Türkiye'de e-belediyecilik hizmetleri ile başlayan ve önemli ilerlemeler kaydedilen bu süreçte belediyelerin kamu hizmetlerinin hemen hemen hepsini dijital ortamda sunması için teknoloji konusunda çalışan özel sektör, kamu sektörü, sivil toplum kuruluşları, akademi ve toplumsal kesimlerin işbirliği içinde gerçekleştirecekleri projelere ihtiyaç vardır. $\mathrm{Bu}$ çerçevede dijital belediyeciliğe dönüşümün gerek kent sakinleri gerekse yönetimler tarafından benimsenmesi ve katılımcı bir yaklaşımla ortak akılda bir araya gelinmesi en önemli faktörlerdendir. Bu girişimlere başlangıç olarak küçük nüfuslu belediyelerde kuluçka merkezleri kurularak dijital belediyecilik test edilebilir. Bu sayede dijital belediyeciliğin Türkiye koşullarında işlevselliği de sınanmış olur.

Belediyelerin iyi yönetişim ilkeleri doğrultusunda katılımcı, şeffaf, hesap verilebilir bir anlayışla vatandaş odaklı hizmet sunumunu gerçekleştirmeleri için blockchain ve yapay zekâ teknolojilerini de göz ardı etmemeleri gerekir. Blockchain teknolojilerinin yerel yönetim birimleri için en önemli faydalarından birisi, işlem kayıtlarının şeffaf olmasının yanında vatandaşların kişisel bilgilerinin mahremiyetini sağlayabilecek bir şifreleme yapısına da sahip olmasıdır (Polat, 2018:41). Yapay zeka teknolojilerini işler hale getiren unsur dijital veridir. Bu bağlamda blockchain ve yapay zeka teknolojilerini dijital belediyecilik ile birleştirerek hızlı, şeffaf, vatandaş katılımıyla iş süreçlerinin tasarlandığı, bürokrasinin en aza indiği, hizmetlerin akıllı sunulduğu yeni bir belediye anlayışı inşa etmek mümkün hale gelecektir.

\section{KAYNAKÇA}

AKSU, Halil (2018), Dijitopya: Dijital Dönüşüm Yolculuk Rehberi, Pusula Yayınları, Ankara, 2. Baskı.

BENLİ, Berrin (2018), “Akıllı Şehirlere Dönüşüm”, Akıllı Belediyecilik Zirvesi 2018 Bildiriler Kitabı (Ed. Yunus Demiryürek ve Kerem Ulusoy), Marmara Belediyeler Birliği Kültür Yayınları, İstanbul, ss.20-25.

BLETZ, Jan (2016), “Molenwaard: The World's First Digital Municipality”, General Case Study, https://joinup.ec.europa.eu/collection/egovernment/document/molenwaard-worlds-first-digitalmunicipality (Erişim Tarihi: 21.09.2019).

ÇAPAR, Mehmet Kürşat (2015), "Dijital Belediyecilik”, Blog, https://www.avd.com.tr/blog/349-dijitalbelediyecilik (Erişim Tarihi: 22.10.2019).

DURAHIM, Ahmet Onur (2018), “Yapay Zeka Teknolojileri”, Akıllı Belediyecilik Zirvesi 2018 Bildiriler Kitabı (Ed. Yunus Demiryürek ve Kerem Ulusoy), Marmara Belediyeler Birliği Kültür Yayınları, İstanbul, ss.31-39.

DIJITALYAZARLAR (2019), “Akillı Şehir (Smart City) Nedir? Neyi Hedeflemektedir?”, Blog, https://www.digitalyazarlar.com/akilli-sehir/ (Erişim Tarihi: 29.10.2019).

ERDOĞAN, Oğuzhan (2019), “Yerel Yönetimlerde Dijital Dönüşüm: Molenwaard Belediyesi Örneği”, Siirt Üniversitesi Sosyal Bilimler Enstitüsü Dergisi, S.7(13), ss.59-74. 
GEMEENTE.NU (2015), "Virtueel Gemeentehuis Molenwaard Wereldberoemd", E-Haber, https://www.gemeente.nu/dienstverlening/ict/virtueel-gemeentehuis-molenwaard-wereldberoemd/ (Erişim Tarihi: 30/10/2019).

HENDEN, H.Burçin ve HENDEN, Rıfkı (2005), "Yerel Yönetimlerin Hizmet Sunumlarındaki Değişim ve EBelediyecilik”, Elektronik Sosyal Bilimler Dergisi, www.e-sosder.com, S.4(14), ss.48-66.

HALMOS, Andrea (2016), "Open Government Use Cases Involving Local And Regional Administrations", Blog, https://ec.europa.eu/futurium/en/content/open-government-use-cases-involving-local-and-regionaladministrations (Erişim Tarihi: 11.10.2019).

İÇIŞLERI BAKANLIĞI E-BELEDIYYE (2019), “Belediyelerde Devrim Niteliğinde Uygulama”, E-Haber, https://www.belediye.gov.tr/belediyelerde-devrim-niteliginde-uygulama (Erişim Tarihi: 11.10.2019).

KARKIN, Naci (2013), "Hollanda Yönetsel Düzeninde Yerel Yönetimler”, Dünyada Yerel Yönetimler Örnekler - Uygulamalar (Ed. Murat Okcu ve Hüseyin Özgür ), Seçkin Yayıncılık, ss.283-308.

KAYPAK, Şafak (2009), “Küreselleşme Sürecinde E-Dönüşüm ve Belediyelere Yansıması”, 7. Uluslararası Bilgi, Ekonomi ve Yönetim Kongresi Bildiri Kitabı, Yalova, ss.215-234.

KAYPAK, Şafak, YILMAZ, Vedat ve BİMAY, Muzaafer (2017), "Dijital Çağda Yerel Yönetimler", Süleyman Demirel Üniversitesi İktisadi ve İdari Bilimler Fakültesi Dergisi, S.22(KAYFOR'15 Özel Say1s1), ss.1798-1813.

MECEK, Mehmet (2017), "E-Devlet ve E-Belediye: Kavramsal Çerçeve ve Türkiye'de Belediye Web Sitelerine Yönelik Yapılan Çalışmaların İncelenmesi”, Süleyman Demirel Üniversitesi İktisadi ve İdari Bilimler Fakültesi Dergisi, S.22(KAYFOR'15 Özel Sayı11), ss.1815-1851.

MERTER, Sümeyra (2012), “E-Municıpalıty In Terms of Local Publıc Services: Beyoğlu Municıpalıty Case”, Yüksek Lisans Tezi, Fatih Üniversitesi Sosyal Bilimler Enstitüsü, İstanbul.

MOLENLANDEN BELEDIYESI (2019), Kurumsal Web Sayfası, https://www.molenlanden.nl/ (Erişim Tarihi: 09.09.2019).

MURPHY, Sean, MCLEARTY, Doug ve COMMISSO, Tim (2018), "Digital Transformation: A Municipal Game Changer", Amo Conference, https://www.amo.on.ca/AMOPDFs/Events/18/Presentations/Monday/Digital-Transformation-MNP-Presentation-Aug-20-F.aspx (Erişim Tarihi: 22.09.2019).

OGD (2013), “Persbericht: OGD Bouwt Eerste Virtuele Gemeentehuis”, Blog, https://blog.ogd.nl/ogd-bouwteerste-virtuele-gemeentehuis (Erişim Tarihi: 11.10.2019).

PEKTAŞ, Ethem Kadri (2011), "Belediye Hizmetlerinde Bilgi-Illetişim Teknolojilerinin Kullanımı ve E-Belediye Uygulamalarındaki Son Gelişmeler: Bir Literatür Taraması”, Sosyal Bilimler Dergisi, S.13(1), ss.65-88.

KARAKAYA POLAT, Rabia (2006), "E-Belediyecilik Kllavuzu Yerel Yönetim Vatandaş Etkiletişimi”, Stratejik Rapor, TASAM Yayınlan, İstanbul.

POLAT, İsmail Hakkı (2018), “Akıllı Belediyecilik ve Blokzincir”, Akıllı Belediyecilik Zirvesi 2018 Bildiriler Kitabı (Ed. Yunus Demiryürek ve Kerem Ulusoy), Marmara Belediyeler Birliği Kültür Yayınları, İstanbul, ss.41-42.

ŞAHİN, Ali (2007), “Türkiye'de E-Belediye Uygulamaları ve Konya Örneği”, Erciyes Üniversitesi İktisadi ve İdari Bilimler Fakültesi Dergisi, S.29, ss.161-189.

VNG (2015), "Local Goverment in The Nerherlands", Drukkerij Excelsior bv, The Hague, https://www.publieksdiensten.nl/wp-content/uploads/2018/04/DENMARK-4-Local-Government-in-theNetherlands.pdf (Erişim Tarihi: 10.10.2019).

YILMAZ, Vedat (2019), "Doğu Anadolu Bölgesinde E-Belediyecilik Hizmetlerinin Yerel Halk Tarafindan Kullanım Düzeylerinin Değerlendirilmesi: Bitlis ve Muş Belediyesi Örnekleri”, E-Yönetişim (Ed. Bekir Parlak ve Kadir Caner Doğan), Beta Yayınevi, İstanbul, ss.509-532. 